Article

\title{
Predictive Value of Pre-Operative 2D and 3D Transthoracic Echocardiography in Patients Undergoing Mitral Valve Repair: Long Term Follow Up of Mitral Valve Regurgitation Recurrence and Heart Chamber Remodeling
}

\author{
Gloria Tamborini ${ }^{1, *(\mathbb{D}}$, Valentina Mantegazza ${ }^{1}$, Marco Penso ${ }^{1}\left(\mathbb{D}\right.$, Manuela Muratori ${ }^{1}$, \\ Laura Fusini ${ }^{1} \mathbb{1}$, Sarah Ghulam Ali ${ }^{1}$, Claudia Cefalù ${ }^{1}$, Gianpiero Italiano ${ }^{1}$, Valentina Volpato ${ }^{1}$, \\ Paola Gripari ${ }^{1}$, Enrico G. Caiani ${ }^{2}{ }^{\mathbb{D}}$, Marco Zanobini ${ }^{1}$ and Mauro Pepi ${ }^{1}$ \\ 1 Centro Cardiologico Monzino, IRCCS, 20138 Milan, Italy; vmantegazza@ccfm.it (V.M.); \\ mpenso@ccfm.it (M.P.); mmuratori@ccfm.it (M.M.); lfusini@ccfm.it (L.F.); sghulamali@ccfm.it (S.G.A.); \\ ccefalu@ccfm.it (C.C.); gitaliano@ccfm.it (G.I.); vvolpato@ccfm.it (V.V.); pgripari@ccfm.it (P.G.); \\ mzanobini@ccfm.it (M.Z.); mpepi@ccfm.it (M.P.) \\ 2 Department of Electronics, Information and Bioengineering, Politecnico di Milano, 20133 Milan, Italy; \\ enrico.caiani@polimi.it \\ * Correspondence: gloria.tamborini@ccfm.it
}

Received: 16 September 2020; Accepted: 20 October 2020; Published: 20 October 2020

\begin{abstract}
The "ideal" management of asymptomatic severe mitral regurgitation (MR) in valve prolapse (MVP) is still debated. The aims of this study were to identify pre-operatory parameters predictive of residual MR and of early and long-term favorable remodeling after MVP repair. We included 295 patients who underwent MV repair for MVP with pre-operatory two- and three-dimensional transthoracic echocardiography (2DTTE and 3DTTE) and 6-months (6M) and 3-years (3Y) follow-up 2DTTE. MVP was classified by 3DTTE as simple or complex and surgical procedures as simple or complex. Pre-operative echo parameters were compared to post-operative values at $6 \mathrm{M}$ and 3Y. Patients were divided into Group $1(6 \mathrm{M}-\mathrm{MR}<2)$ and Group $2(6 \mathrm{M}-\mathrm{MR} \geq 2)$, and predictors of MR $\geq 2$ were investigated. MVP was simple in $178 / 295 \mathrm{pts}$, and $94 \%$ underwent simple procedures, while in only 42/117 (36\%) of complex MVP a simple procedure was performed. A significant relation among prolapse anatomy, surgical procedures and residual MR was found. Post-operative MR $\geq 2$ was present in 9.8\%: complex MVP undergoing complex procedures had twice the percentage of MR $\geq 2$ vs. simple MVP and simple procedures. MVP complexity resulted independent predictor of $6 \mathrm{M}-\mathrm{MR} \geq 2$. Favorable cardiac remodeling, initially found in all cases, was maintained only in MR $<2$ at 3Y. Pre-operative 3DTTE MVP morphology identifies pts undergoing simple or complex procedures predicting MR recurrence and favorable cardiac remodeling.
\end{abstract}

Keywords: mitral valve prolapse; mitral valve repair; three-dimensional echocardiography; primary mitral regurgitation; mitral valve disease

\section{Introduction}

Myxomatous or degenerative mitral valve (MV) disease is the leading cause of MV prolapse (MVP) and surgically correctable mitral regurgitation (MR) in the developed world. International guidelines suggest early MV repair prior to the development of symptoms or left ventricular (LV) dysfunction [1]. However, the correct timing of MV repair is still under debate, and discordance between observational investigations of watchful waiting and early surgery management strategies drives the continued 
controversy surrounding this issue [2-5]. In this regard, recent guidelines stated that MV repair can be considered in asymptomatic patients when there is a high likelihood of durable result at very low risk $(<1 \%$ mortality). Results in terms of reparability and recurrence of MR are related to clinical (younger age) and surgical factors (simple versus complex surgical procedures) [6-9] and varies in different studies. Since more complex surgical procedures are mainly indicated in cases with more complex prolapses and vice versa, noninvasive pre-operative assessment of MV anatomy is essential to define feasibility and complexity of repair. Moreover, three-dimensional (3D) transthoracic echocardiography (TTE) is nowadays a very robust technique that allows a very precise localization and definition of MV pathology and a comprehensive two-dimensional (2D) TTE, and 3DTTE evaluation may, therefore, include all morphologic, hemodynamic and functional data [10-14]. The aims of this study in a large series of patient undergoing MV repair for severe MVP were: (a) to evaluate whether 3DTTE may identify cases undergoing simple vs. complex surgical procedures based on the MVP complexity; (b) to correlate MVP complexity and surgical techniques to outcomes in terms of 6 months (6M) and 3 years (3Y) MR residual severity; (c) to correlate all these findings (mainly optimal results vs. recurrence of MR) to left chamber remodeling and functional and hemodynamic parameters at $6 \mathrm{M}$ and $3 \mathrm{Y}$ follow-up.

\section{Methods}

Between 2008 and 2018, 1000 cases with severe MR due to MVP underwent early MV repair in Centro Cardiologico Monzino IRCCS. We retrospectively selected all consecutive cases with a pre-operative 2DTTE and a 3DTTE as well as a 2DTTE at 6M and 3Y follow-up. Of the 1000 cases, 13 patients were excluded for an insufficient quality of 3DTTE reconstruction, 541 patients because after MV repair the requested follow-up was not available and 51 cases because they underwent MV replacement after a first attempt of repair. Thus, our final study population was represented by 295 patients. The local research committee approved this retrospective study protocol (reference $\mathrm{N}^{\circ}$ R1262/20-CCM 1326) and all study participants provided written informed consent.

All the 295 patients in the study population underwent a 2DTTE and 3DTTE within 1 month prior to surgery. Two-dimensional and 3DTTE were performed using 2 ultrasound platforms (iE33 or EPIQ 7C) both equipped with the X5-1 probe (Philips Medical Systems, Andover, MA, USA).

From 2DTTE, we derived left ventricular (LV) end-diastolic (EDVI) and end-systolic (ESVI) volumes indexed for body surface area (BSA); LV ejection fraction (EF), LV stroke volume (SV), left atrial volume indexed for BSA (LAVI) using the biplane Simpson's method. Grading of tricuspid regurgitation (mild $=1$, moderate $=2$, severe $=3$ ) was obtained according to guidelines [15]. Pulmonary artery systolic pressure (PASP) was calculated using the Doppler echocardiographic method [16].

All pre-op 2DTTE and 3DTTE images were retrospectively analyzed by a single experienced echocardiographer, blinded to the intraoperative findings. The Carpentier nomenclature was applied to the MV leaflets [16]. The presence of ruptured chordae, clefts, annular or leaflet severe calcifications was annotated. MVP was defined as simple or complex: simple anatomical lesions included isolated P2 prolapse or P2 associated with P1 or P3. According to literature [3,17-20], cases including lesions involving $>2$ posterior leaflet scallops, anterior or both leaflets, commissures or with severe annular or leaflet calcifications were defined as complex. The 2 main phenotypes of MVP were also distinguished: Barlow disease (mixomatous leaflet degeneration, elongated and thickened chordae, dilated annulus) and fibroelastic deficiency (FED) (normal/thinner leaflets, frequent single segment prolapse with chordal rupture) [9,17-19].

To assess reproducibility of MVP evaluation (prolapsing scallop identification), intraobserver variability was performed by the same reader after $\geq 1$ month; interobserver variability was performed by a second experienced reader, blinded to the previous results

Echocardiographic MVP evaluation was compared with MV anatomical inspection performed by the operating surgeon. 
Protocols and reports of surgical techniques were annotated in detail. According to literature data [20-22] and surgical institutional experience, surgical procedures were divided into simple vs. complex techniques. Recently, the complexity of surgical procedures was better defined $[23,24]$.

Other associated procedures were recorded.

A score of 1 (mild), 2 (mild-to-moderate), 3 (moderate-to-severe) or 4 (severe) was assigned to MR integrating both qualitative and quantitative parameters [15,25]. Based on 6M-MR, patients were divided into Group 1 (residual MR $<2$ ) and Group 2 (residual MR $\geq 2$ ). Differences in left chamber volumes and functional parameters, pre-op MVP morphology (complex vs. simple) and surgical procedure (complex vs. simple) were compared between the 2 groups and analyzed to identify outcome predictors.

Continuous data are reported as the mean \pm standard deviations, whereas categorical data as absolute frequencies (percentages). A test of normality (Shapiro-Wilk test) was performed on continuous data. Continuous variables were compared using the unpaired Student's t-test (and the Welch's corrected version, as appropriate) or the Mann-Whitney U test, whilst a $\chi^{2}$ test was applied for categorical data. Repeated measures one-way ANOVA test or Friedman test with the Bonferroni correction were used to evaluate TTE mean values at baseline, 6M and 3Y. Inter- and intraobserver correlations were performed using Pearson coefficient. Kruskal Wallis and Mann-Whitney U test with Bonferroni correction was used to compare residual mitral regurgitation in each group of patients according to MVP anatomy and surgery technique All results were considered significant with $p$-value $<0.05$. Echocardiographic parameters as well as baseline prolapse and procedure characteristics with a $p$-value $<0.10$ at univariate logistic analysis were used for the multivariate logistic regression analysis with the enter method for the identification of independent variables associated with the outcome. All the statistical analyses were implemented using IBM SPSS 25.

\section{Results}

Patient characteristics data in the whole study population and in each group of patients are shown in Table 1.

Table 1. Mean $\pm \mathrm{SD}$ and/or frequencies of baseline clinical characteristics of the study population.

\begin{tabular}{ccccc}
\hline & $\begin{array}{c}\text { Overall } \\
\text { Population } \\
(n=295)\end{array}$ & $\begin{array}{c}\text { Group 1: } \\
\text { 6M-MR }<2 \\
(n=266)\end{array}$ & $\begin{array}{c}\text { Group 2: } \\
\text { 6M-MR } \geq 2 \\
(n=29)\end{array}$ & $p$ Value \\
\hline Age (years) & $60 \pm 13$ & $60 \pm 12$ & $63 \pm 15$ & 0.116 \\
\hline Men & $197(66.8 \%)$ & $182(68.4 \%)$ & $15(51.7 \%)$ & 0.070 \\
\hline Body surface area $\left(\mathrm{m}^{2}\right)$ & $1.8 \pm 0.2$ & $1.8 \pm 0.2$ & $1.8 \pm 0.2$ & 0.084 \\
\hline Atrial fibrillation & $24(8.1 \%)$ & $22(8.3 \%)$ & 0.797 \\
\hline Etiology & & & 0.654 \\
\hline FED & $71(24.1 \%)$ & $65(24.4 \%)$ & 0.028 \\
\hline Barlow & $224(75.9 \%)$ & $201(75.6 \%)$ & $23(79.3 \%)$ & \\
\hline Prolapse anatomy & & & \\
\hline Simple & $178(60.3 \%)$ & $166(62.4 \%)$ & $12(41.4 \%)$ & \\
\hline Complex & $117(39.7 \%)$ & $100(37.6 \%)$ & $17(58.6 \%)$ & \\
\hline Type of procedure & & & \\
\hline Simple & $196(66.4 \%)$ & $182(68.4 \%)$ & $14(48.3 \%)$ \\
\hline Complex & $99(33.6 \%)$ & $84(31.6 \%)$ & $15(51.7 \%)$ \\
\hline 6M-MR: residual mitral regurgitation at 6-month follow-up. &
\end{tabular}


Age $(58 \pm 14$ vs. $61 \pm 11, p<0.05)$ and BSA $\left(1.78 \pm 0.19\right.$ vs. $\left.1.84 \pm 0.14 \mathrm{~cm}^{2}, p<0.05\right)$ were significantly lower in complex in comparison with simple MVP. A complex MVP was more frequent in Barlow's disease patients (98/224, 43.7\%) in comparison with FED (19/71, 26.7\%). There was close agreement in echocardiographic MVP assessment both between the 2 different observers (interobserver variability: $\mathrm{r}=0.88, p<0.001$ ), and between the repeated measurement of the same observer (intraobserver variability: $\mathrm{r}=0.96 p<0.001$ ). Surgical inspection confirmed echocardiographic diagnosis of the prolapsing scallops in 292/295 cases (98.9\%). In 3 cases without agreement between surgical inspection and echocardiographic diagnosis, the anatomical findings did not change MVP classification (simple or complex). Table 2 shows surgical techniques for MV repair and associated procedures performed.

Table 2. Surgical techniques used in the study population.

\begin{tabular}{cc}
\hline \multicolumn{3}{c}{ Simple Surgical Techniques for Mitral Valve Repair } \\
\hline Quadrangular resection of posterior leaflet & $292(98.9 \%)$ \\
Annuloplasty & $294(99.6 \%)$ \\
Sliding of posterior leaflet/Posterior leaflet folding plasty & $112(38 \%)$ \\
Edge-to-edge technique & $30(1 \%)$ \\
Posterior annular plication & $88(29.3 \%)$ \\
Commissural fusion or Cleft Closure & $28(9.4 \%)$ \\
\hline Complex Surgical Techniques for Mitral Valve Repair \\
\hline Replacement or transfer of chordae tendinae & $71(24 \%)$ \\
Papillary muscle repositioning & $44(14.9 \%)$ \\
\hline Other Associated Procedures & \\
\hline Aorto-coronary bypass graft & $31(10 \%)$ \\
Tricuspid valve annuloplasty & $48(16.2 \%)$ \\
Aortic valve/root replacement & $23(7.8 \%)$ \\
Atrial fibrillation ablation & $23(7.8 \%)$ \\
Atrial appendage closure & $17(5.7 \%)$ \\
Patent forame ovale closure & $7(2.3 \%)$ \\
\hline
\end{tabular}

A simple surgical procedure was realized in most of simple MVPs; conversely, complex procedures were performed in the majority of complex prolapses (Figure 1).

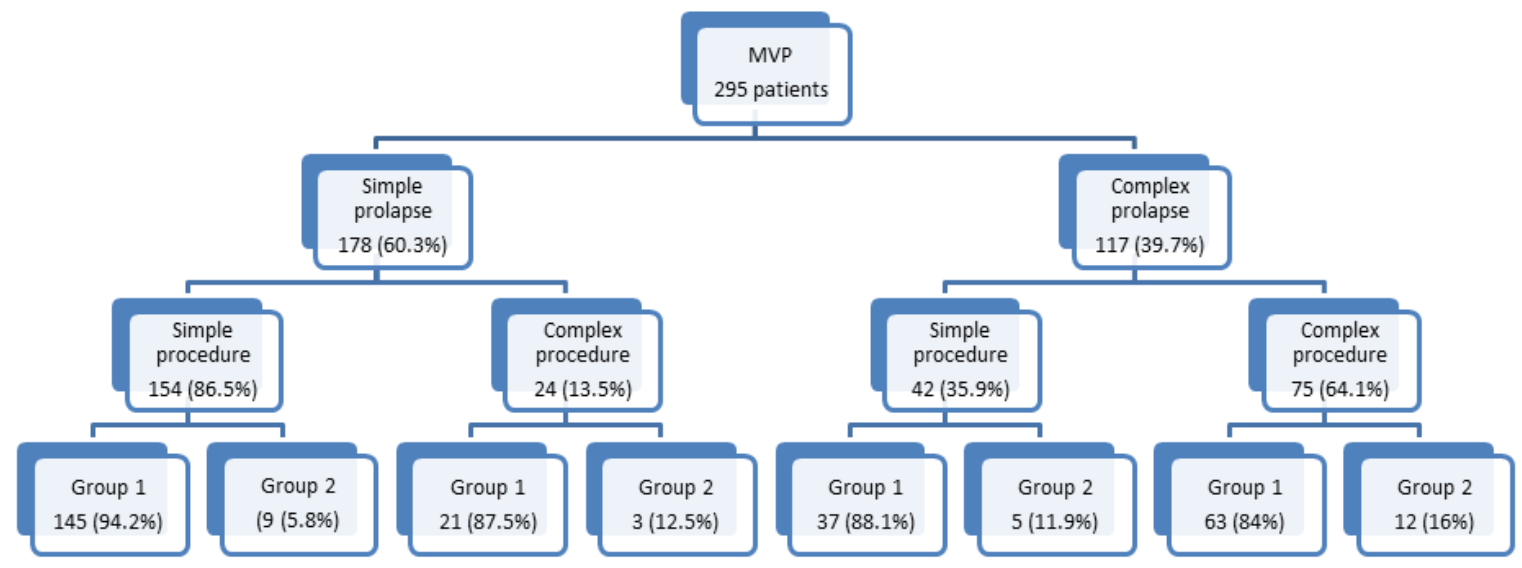

Figure 1. Flow-chart scheme showing the number and percentage of cases with simple vs. complex mitral valve lesions, types of cardiac surgery according to complexity of mitral lesions and 6 month residual mitral valve regurgitation $\leq 2$ (Group1) or $>2$ (Group 2). MVP = mitral valve prolapse.

Baseline, 6M and 3Y 2DTTE parameters are summarized in Table 3. 
Table 3. Mean \pm SD for $2 \mathrm{D}$ transthoracic echocardiographic parameters at baseline and at 6 months and 3 years follow-up.

\begin{tabular}{|c|c|c|c|c|}
\hline & Basal & 6 Months & 3 Years & $p$-Value \\
\hline \multicolumn{5}{|c|}{ All Patients (295 patients) } \\
\hline Mitral regurgitation grade & $3.9 \pm 0.2$ & $0.6 \pm 0.7$ * & $0.9 \pm 0.9^{\dagger, *}$ & $<0.001$ \\
\hline Left ventricular end diastolic volume index $\left(\mathrm{mL} / \mathrm{m}^{2}\right)$ & $77.4 \pm 19.3$ & $57.3 \pm 14.9 *$ & $56.9 \pm 17.8 *$ & $<0.001$ \\
\hline Left ventricular end systolic volume index $\left(\mathrm{mL} / \mathrm{m}^{2}\right)$ & $27.0 \pm 9.6$ & $24.6 \pm 10.7 *$ & $23.9 \pm 12.3$ * & $<0.001$ \\
\hline Left ventricular stroke volume index (mL/mq) & $50.4 \pm 12.8$ & $32.6 \pm 7.5 *$ & $32.9 \pm 8.3^{*}$ & $<0.001$ \\
\hline Left ventricular ejection fraction (\%) & $65.2 \pm 6.8$ & $57.9 \pm 8.0 *$ & $59.2 \pm 7.7^{\dagger, *}$ & $<0.001$ \\
\hline Left atrial volume index $\left(\mathrm{mL} / \mathrm{m}^{2}\right)$ & $66.4 \pm 24.8$ & $45.4 \pm 17.7 *$ & $44.5 \pm 18.5 *$ & $<0.001$ \\
\hline Tricuspid regurgitation grade & $1.0 \pm 0.8$ & $0.9 \pm 0.4$ & $1.0 \pm 0.4^{\dagger}$ & 0.024 \\
\hline Pulmonary artery systolic pressure $(\mathrm{mmHg})$ & $36.4 \pm 11.1$ & $28.1 \pm 5.9 *$ & $29.5 \pm 7.6^{\dagger, *}$ & $<0.001$ \\
\hline \multicolumn{5}{|c|}{ Group 1: 6M-MR < 2 (266 patients) } \\
\hline Mitral regurgitation grade & $3.9 \pm 0.2$ & $0.4 \pm 0.4$ * & $0.7 \pm 0.7^{*,+}$ & $<0.001$ \\
\hline Left ventricular end diastolic volume index $\left(\mathrm{mL} / \mathrm{m}^{2}\right)$ & $77.0 \pm 18.9$ & $56.7 \pm 14.6^{*}$ & $55.9 \pm 17.0 *$ & $<0.001$ \\
\hline Left ventricular end systolic volume index $\left(\mathrm{mL} / \mathrm{m}^{2}\right)$ & $26.8 \pm 9.2$ & $24.5 \pm 10.7 *$ & $23.4 \pm 11.9$ * & $<0.001$ \\
\hline Left ventricular stroke volume index $\left(\mathrm{mL} / \mathrm{m}^{2}\right)$ & $50.1 \pm 12.7$ & $32.2 \pm 7.2 *$ & $32.5 \pm 8.0 *$ & $<0.001$ \\
\hline Left ventricular ejection fraction $(\%)$ & $65.2 \pm 6.7$ & $57.7 \pm 7.8 *$ & $59.3 \pm 7.6^{\dagger, *}$ & $<0.001$ \\
\hline Left atrial volume index $\left(\mathrm{mL} / \mathrm{m}^{2}\right)$ & $66.1 \pm 24.4$ & $44.5 \pm 17.5 *$ & $43.1 \pm 17.7^{\dagger, *}$ & $<0.001$ \\
\hline Tricuspid regurgitation grade & $1.0 \pm 0.8$ & $0.9 \pm 0.3$ & $1.0 \pm 0.4$ & 0.066 \\
\hline Pulmonary artery systolic pressure $(\mathrm{mmHg})$ & $35.4 \pm 9.8$ & $27.7 \pm 5.6^{*}$ & $28.7 \pm 6.8^{*}$ & $<0.001$ \\
\hline \multicolumn{5}{|c|}{ Group 2: 6M-MR $\geq 2$ (29 patients) } \\
\hline Mitral regurgitation grade & $3.9 \pm 0.3$ & $2.1 \pm 0.3^{\ddagger, *}$ & $2.7 \pm 0.7 \ddagger,+, *$ & $<0.001$ \\
\hline Left ventricular end diastolic volume index $\left(\mathrm{mL} / \mathrm{m}^{2}\right)$ & $82.2 \pm 22.8$ & $62.9 \pm 16.0^{\ddagger}, *$ & $66.0 \pm 22.0 \ddagger * *$ & $<0.001$ \\
\hline Left ventricular end systolic volume index $\left(\mathrm{mL} / \mathrm{m}^{2}\right)$ & $29.4 \pm 12.7$ & $25.9 \pm 10.7$ & $28.8 \pm 14.7 \ddagger$ & 0.263 \\
\hline Left ventricular stroke volume index $\left(\mathrm{mL} / \mathrm{m}^{2}\right)$ & $52.7 \pm 13.6$ & $37.0 \pm 8.8^{\ddagger, *}$ & $37.1 \pm 9.6 \ddagger$ & $<0.001$ \\
\hline Left ventricular ejection fraction $(\%)$ & $65.1 \pm 7.7$ & $59.8 \pm 9.6 *$ & $57.8 \pm 8.2 *$ & $<0.001$ \\
\hline Left atrial volume index $\left(\mathrm{mL} / \mathrm{m}^{2}\right)$ & $68.9 \pm 28.1$ & $53.6 \pm 17.6^{\ddagger, *}$ & $56.6 \pm 21.8^{\ddagger, *}$ & 0.002 \\
\hline Tricuspid regurgitation grade & $1.3 \pm 1.0$ & $1.1 \pm 0.7$ & $1.3 \pm 0.7 \ddagger$ & 0.270 \\
\hline Pulmonary artery systolic pressure $(\mathrm{mmHg})$ & $45.2 \pm 16.8 \ddagger$ & $31.8 \pm 7.4^{\ddagger, *}$ & $37.0 \pm 10.1^{\ddagger, t, *}$ & $<0.001$ \\
\hline
\end{tabular}

${ }^{*} p<0.05$ : vs. baseline, ${ }^{\dagger} p<0.05$ : vs. 6 months, ${ }^{\ddagger} p<0.05$ : mitral regurgitation $\geq 2$ vs. $<2$. 
Residual MR increased significantly from 6M to 3Y both in patients with simple MVP and with complex prolapse. However, at $3 Y$, patients with simple MVP and simple surgery had alower increase in comparison with cases with complex MVP and complex surgery (Table 4)

Table 4. Six-months and 3-years residual mitral regurgitation according to MVP anatomy and surgery technique reported as median (25th-75th percentile).

\begin{tabular}{cccc}
\hline & 6 Months & 3 Years & $p$-Value \\
\hline Simple MVP + simple surgery & $0.50(0.00-1.00)$ & $0.75(0.00-1.00) *$ & $<0.001$ \\
\hline Simple MVP + complex surgery & $0.25(0.00-1.00)$ & $0.75(0.12-1.37) *$ & 0.003 \\
\hline Complex MVP + simple surgery & $0.50(0.00-1.00)$ & $1.00(0.50-1.00) *$ & 0.002 \\
\hline Complex MVP + complex surgery & $0.50(0.00-1.00)$ & $1.00(0.50-2.00) *$ *\# & $<0.001$ \\
\hline${ }^{*} p<0.05,6$ months vs. 3 years; ${ }^{*} p<0.05$ significant difference in increase in MR severity among groups.
\end{tabular}

After surgery reduction in LVEDVI, LVESVI and left atrial volumes were observed at $6 \mathrm{M}$. The expected reduction in MR after MV repair was also associated with a reduction in LVSVI, LVEF and PASP. At 3Y no additional changes were found in LV and left atrial parameters, while a mild but significant increase in PASP was observed. Based on $6 \mathrm{M}$ residual MR, 266 patients were included in Group $1(6 \mathrm{M}-\mathrm{MR}<2)$ and 29 in Group $2(6 \mathrm{M}-\mathrm{MR} \geq 2)$. No differences in gender, age, BSA or incidence of atrial fibrillation were observed between the 2 groups. (Table 1). No significant differences in pre-operative echo data were present between Group 1 and Group 2 with the exception of PASP which was significantly higher in Group 2.

At $6 \mathrm{M}$, changes in left cardiac chambers and PASP were similar to the all population although reduction in LVESVI did not reach statistical significance in Group 2. At 3Y, both groups showed marked differences both in MR severity, chambers remodeling and PASP. Indeed, in Group 1 no differences were observed in LV volumes or PASP at $3 Y$ vs. $6 \mathrm{M}$ data. On the contrary, a small but significant decrease in LAVI and an improvement in LVEF was present. In Group 2, a trend towards larger left chambers volumes and lower LVEF was observed at $3 \mathrm{Y}$ vs. $6 \mathrm{M}$, associated with a significant increase in PASP. Residual MR $\geq 2$ was significantly more frequent in complex MVP in comparison with simple cases and, as expected, after complex surgery than after a simple procedure.

$\mathrm{X}^{2}$ analysis demonstrated a significant relationship between prolapse anatomy, type of procedure and residual $6 \mathrm{M}-\mathrm{MR}$. The percentage of patients with complex MVP undergoing complex procedure with residual $M R \geq 2$ is more than twice than the percentage of patients with simple prolapse undergoing simple procedures (5.8\% vs. 16\%). At univariate analysis PASP, LVSVI, MVP morphology (simple vs. complex) and procedure (simple vs. complex) were the only independent predictors of MR $\geq 2$ (Table 5).

We identified from the baseline parameters the complex MVP, complex procedure, PASP as independent predictors of the MR at $6 \mathrm{M}$. At multivariate analysis, MVP complexity and PASP were found as independent predictors of $6 \mathrm{M}-\mathrm{MR} \geq 2$.

Figure 2 shows 2 examples of MVP before surgery and at $6 \mathrm{M}$ and $3 \mathrm{Y}$. 
Table 5. Results of univariate and multivariate analysis for the identification of independent variables predicting residual mitral regurgitation $\geq 2$.

\begin{tabular}{ccccc}
\hline & \multicolumn{2}{c}{ Univariate Model } & \multicolumn{1}{c}{ Multivariate Model } \\
\cline { 2 - 5 } & OR (95\% CI) & $p$ Value & OR (95\% CI) & $p$ Value \\
\hline Male & $0.747(0.396-1.408)$ & 0.367 & & \\
\hline Age (years) & $1.009(0.984-1.034)$ & 0.490 & & \\
\hline Body surface area $\left(\mathrm{m}^{2}\right)$ & $0.984(0.204-4.754)$ & 0.984 & & \\
\hline Antero-posterior mitral anulus diameter $(\mathrm{mm})$ & $1.009(0.951-1.070)$ & 0.774 & & \\
\hline Medio-lateral mitral anulus diameter $(\mathrm{mm})$ & $0.996(0.935-1.061)$ & 0.906 & & $<0.001$ \\
\hline Left ventricular stroke volume index $(\mathrm{mL} / \mathrm{mq})$ & $1.020(0.998-1.044)$ & 0.081 & $1.018(0.993-1.043)$ & \\
\hline Left ventricular ejection fraction $(\%)$ & $0.989(0.945-1.034)$ & 0.628 & & \\
\hline Left atrial volume index $(\mathrm{mL} / \mathrm{mq})$ & $1.005(0.994-1.017)$ & 0.377 & & \\
\hline Tricuspid regurgitation $\geq 2$ & $0.619(0.303-1.262)$ & 0.187 & & \\
\hline Systolic pulmonary pressure $(\mathrm{mmHg})$ & $1.054(1.028-1.082)$ & $<0.001$ & $1.056(1.029-1.084)$ & \\
\hline Etiology (Presence of fibroelastic deficiency) & $1.764(0.785-3.965)$ & 0.169 & & 0.247 \\
\hline Complex mitral valve prolapse & $0.425(0.228-0.792)$ & 0.007 & $0.414(0.215-0.798)$ & 0.08 \\
\hline Complex surgical procedure & $0.457(0.245-0.851)$ & 0.014 & $0.646(0.297-1.407)$ & \\
\hline
\end{tabular}
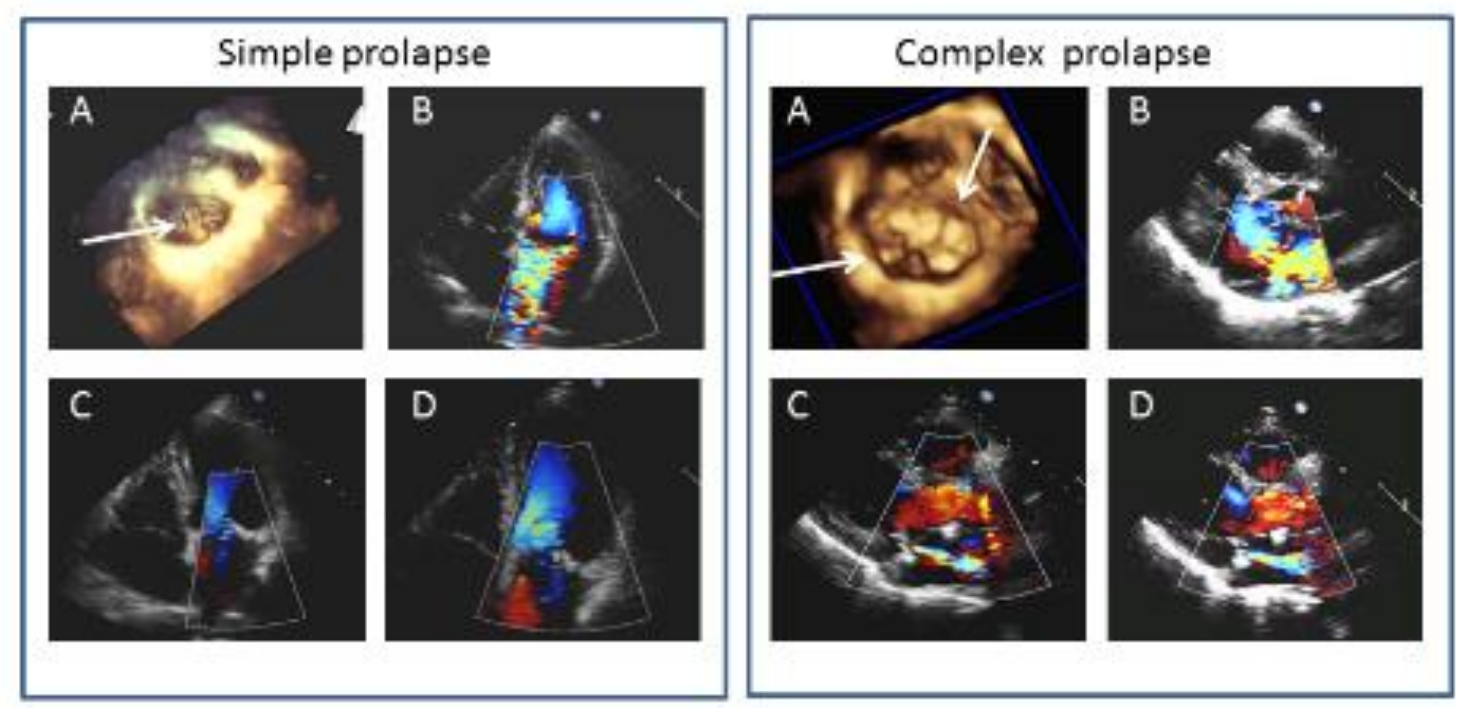

Figure 2. Left panels: Example of simple mitral valve prolapse (MVP). (A) surgical view of three-dimensional MVP reconstruction showing P2 prolapse with multiple chordal ruptures (arrow). (B) two-dimensional transthoracic 4 chamber apical view showing a severe mitral regurgitation (MR). (C,D) two-dimensional transthoracic 4 chamber apical views at $6 \mathrm{M}$ and $3 \mathrm{Y}$ follow-up, respectively, with trivial MR. Right panels: example of complex MVP. (A) surgical view of three-dimensional MVP reconstruction showing A2, A3, P2 prolapse (arrows) (B) two-dimensional transthoracic parasternal view showing severe MR central jet. (C,D) two-dimensional parasternal long axis views at $6 \mathrm{M}$ and $3 \mathrm{Y}$ follow-up, respectively, with mild to moderate MR.

\section{Discussion}

The mean findings of this study are (a) 3DTTE may facilitate the evaluation of MV morphology in patients with MVP undergoing surgical repair; (b) a comprehensive 2DTTE and 3DTTE allowed to discriminate simple vs. complex lesions and to facilitate the prediction of surgical procedures. In cases with simple lesions undergoing simple procedures, the absence of significant MR at follow-up correlated with favorable LV and left atrial remodeling and normalization of PASP. Recurrence of MR $\geq 2$ at $3 Y$ occurred in a small subgroup of patients undergoing complex procedures for complex lesions, 
and in these cases, after an initial favorable LV and left atrial remodeling at $6 \mathrm{M}$ a trend towards larger left chamber volumes and lower LVEF as well as a significant increase in PASP was observed at 3Y. Thus, pre-operative 2DTTE and 3DTTE may facilitate the prediction of surgical complexity, and results in terms of MR recurrence and heart remodeling.

Three-dimensional TTE may be performed routinely as previously demonstrated [10-14] and an accurate assessment of MV morphology may be easily obtained. Indeed, even though 3DTEE provides MV images of extraordinary quality with a very high accuracy in the identification of all scallops, head-to-head comparison among 2D-3DTTE and 2D-3DTEE confirmed previous data suggesting that besides overall 3DTEE accuracy being the highest over every other echocardiographic techniques, 3DTTE accuracy is similar to 2DTEE (central scallops) or slightly superior (lateral and medial scallops) than 2DTEE [10]. Therefore, a comprehensive transthoracic approach may include not only all standard echo-Doppler measurements but also 3D morphology of the MV. This may be particularly useful in the follow-up of patients avoiding TEE studies or performing TEE studies only when TTE is suboptimal or when specific MV details have to be further investigated before surgery.

Moreover, it has been previously demonstrated that 3DTTE is feasible, timesaving and accurate in identifying simple vs. complex MVP [12]. Recently new advantages in 3D technology further facilitated visualization of the MV. Imaging quality is also improved, and good or optimal quality was found in the majority of cases confirming also a 95\% overall accuracy of 3DTTE in the recognition of MV lesions. This percentage was obtained in this large (295 patients) unselected population-a percentage similar to previous 2DTTE and 3DTTE studies [10-12].

Early surgery prior to the development of symptoms and LV dysfunction is recommended independently on MV complexity. Javadikasgari et al. recently demonstrated that valve repair was associated with similarly low operative risk- and time-related survival but less durability in complex disease [3]. Indeed, several studies showed that patients with simple and complex degenerative MR undergoing MV repair, despite similar low operative risk may have different long-term outcomes [4-8]. Earlier operation and placing artificial chordae in complex MV disease and not having leaflet resection and annuloplasty were associated with lower durability of MV repair. In the last two decades, patients have been referred for early correction of severe MR regardless of the type and extent of MVP. In a recent review, David [5] stated that MV repair for degenerative MR is associated with a low probability of reoperation for up to two decades after surgery. However, almost one-third of the patients develop recurrent moderate or severe MR suggesting that surgery does not arrest the degenerative process. [6]. Other anatomical characteristics may also affect surgical outcomes, and Fusini [26] showed that mitral annular calcification is a relative common finding in MVP and demonstrated in a series of 410 patients that $8 \%$ of cases with annular calcifications underwent replacement after a first attempt of repair vs. $3 \%$ without. For all these reasons, the correct timing of asymptomatic patients with severe MR is still under debate, and guidelines [1] not only state that MV repair can be considered when there is a high likelihood of durable MV repair at low risk but also introduced detailed characteristics of the ideal candidate for early surgery.

In our study, we sought to demonstrate that a comprehensive 2D and 3DTTE may orient to the correct timing of surgery and may predict cases with a lower probability of durable MV repair. The large majority of patients in our series had excellent early and long-term results and only 29 out of 295 patients (9\%) had a MR $\geq 2$ at 3Y. Interestingly, MVP complexity as well as procedure complexity correlated to outcomes. The number of cases with $M R \geq 2$ at $3 Y$ that have performed a complex procedure was more than twice than the percentage of simple prolapse and simple procedures with $\mathrm{MR} \geq 2(16 \%$ vs. $5.8 \%)$. Moreover, cases with more complex MVP and suboptimal results also had other pre-operative characteristics such as higher grade of tricuspid regurgitation and higher PASP. At multivariate analysis, only MVP anatomy and baseline PASP were independent predictors of residual MR.

To prevent irreversible LV dysfunction that may occur despite an apparently "normal" LV with a preserved LVEF, guidelines suggest early MV repair (when feasible) in asymptomatic patients 
with preserved LV systolic function. This strategy not only avoids the appearance of symptoms (in the "old" strategy of waiting for symptoms, MV repair was associated with the worst prognosis, in terms of post-operative mortality and risk of heart failure) but allows a favorable LV and left atrial remodeling [27-29]. Novelties of this study are that the remodeling of LV, left atrium and changes in hemodynamic status correlated to the pre-operative comprehensive echo-Doppler values, to the MVP characteristics and to surgical results in terms of residual MR both at early post-operative observation and at long term follow-up.

We selected consecutive asymptomatic patients undergoing MV repair who had a complete clinical and echo-Doppler follow-up. All cases had favorable remodeling of LAVI and LVEDVI, associated with a mild decrease in LVEF and reduction in PASP. However, patients with residual MR $\geq 2$ differed significantly in terms of early and mainly late remodeling and hemodynamics. At 3Y, LAVI and LV volumes were steadily reduced in patients with optimal MV repair results $(M R<2)$, while the minority of cases with suboptimal results showed an initial favorable remodeling that did not persist at $3 \mathrm{Y}$. Accordingly, PASP significantly decreased in both groups in the early post-operative period, but only in cases with suboptimal repair it significantly increased thereafter.

Suri [30] demonstrated that early repair of MVP, before deterioration in left heart size or function, increases the likelihood of subsequent normalization of LVEF. Our data confirmed favorable remodeling of left heart chambers associated with values of LVEF within the range of normality throughout the follow-up. Interestingly early mild decrease in LVEF after repair (as expected due to increased afterload) and tendency to increase values at 3Y occurred in Group 1, whereas LVEF was steadily reduced at 3Y in comparison to pre-operative values (even though in the range of normal values) in Group 2.

Our data finally support the role of 3DTTE not only in patients in patients in whom the surgical indication is obvious, but also in the pre-operative follow-up of patients without surgical indication in whom serial examinations are very useful to determine the correct surgical timing. Therefore, a comprehensive 2D and 3DTTE may reduce the need for a TEE approach. Indeed, our data showed that the overwhelming majority of cases with simple lesions underwent a simple surgical technique, while patients with complex prolapse could be treated by simple or complex successful MV repair. Moreover, the recurrence of $\mathrm{MR} \geq 2$ at $6 \mathrm{M}$ and the MR increase at $3 \mathrm{Y}$ are higher in cases undergoing complex procedures for complex lesions.

\section{Conclusions}

The complexity of MV repair procedure may be predicted by a comprehensive 2DTTE and 3DTTE, thus facilitating the correct timing of surgery (early vs. late procedure). Finally, correct timing in cases with optimal early and late results is related to normalization of left heart chamber volumes, maintenance of normal LVEF and normalization of PASP, while after an initial favorable LV and LAVI remodeling at $6 \mathrm{M}$, a trend towards larger left chamber volumes and lower LVEF was observed associated with a significant increase in PASP at $3 \mathrm{Y}$ in cases with residual significant MR.

Author Contributions: Conceptualization, G.T., V.M. and M.P. (Mauro Pepi); Data curation, V.M. and C.C.; Formal analysis, M.P. (Marco Penso). and L.F.; Investigation, M.M., S.G.A., G.I., V.V., P.G. and M.Z.; Methodology, G.T., M.P. (Marco Penso), L.F. and C.C.; Supervision, E.G.C. and M.P. (Mauro Pepi); Validation, M.M., S.G.A., G.I., V.V., P.G. and M.Z.; Visualization, G.T.; Writing-original draft, G.T.; Writing-review and editing, M.P. (Mauro Pepi). All authors have read and agreed to the published version of the manuscript.

Funding: This research received no external funding.

Conflicts of Interest: Volpato is on speaker bureau for Philips Healthcare. 


\section{References}

1. Nishimura, R.A.; Otto, C.M.; Bonow, R.O.; Carabello, B.A.; Erwin, J.P.; Fleisher, L.A.; Jneid, H.; Mack, M.J.; McLeod, C.J.; O'Gara, P.T.; et al. 2017 AHA/ACC Focused Update of the 2014 AHA/ACC Guideline for the Management of Patients With Valvular Heart Disease: A Report of the American College of Cardiology/American Heart Association Task Force on Clinical Practice Guidelines. Circulation 2017, 135, e1159-e1195. [CrossRef]

2. Suri, R.M.; Vanoverschelde, J.-L.; Grigioni, F.; Schaff, H.V.; Tribouilloy, C.; Avierinos, J.-F.; Barbieri, A.; Pasquet, A.; Huebner, M.; Rusinaru, D.; et al. Association Between Early Surgical Intervention vs Watchful Waiting and Outcomes for Mitral Regurgitation Due to Flail Mitral Valve Leaflets. JAMA 2013, 310, 609-616. [CrossRef] [PubMed]

3. Javadikasgari, H.; Mihaljevic, T.; Suri, R.M.; Svensson, L.G.; Navia, J.L.; Wang, R.Z.; Tappuni, B.; Lowry, A.M.; McCurry, K.R.; Blackstone, E.H.; et al. Simple versus complex degenerative mitral valve disease. J. Thorac. Cardiovasc. Surg. 2018, 156, 122-129.e16. [CrossRef]

4. David, T.E.; Armstrong, S.; McCrindle, B.W.; Manlhiot, C. Late Outcomes of Mitral Valve Repair for Mitral Regurgitation Due to Degenerative Disease. Circulation 2013, 127, 1485-1492. [CrossRef]

5. David, T.E. Durability of mitral valve repair for mitral regurgitation due to degenerative mitral valve disease. Ann. Cardiothorac. Surg. 2015, 4, 417-421.

6. Gardner, M.A.; Hossack, K.F.; Smith, I. Long-Term Results Following Repair for Degenerative Mitral Regurgitation-Analysis of Factors Influencing Durability. Hear. Lung Circ. 2019, 28, 1852-1865. [CrossRef]

7. Flameng, W.J.; Meuris, B.; Herijgers, P.; Herregods, M.-C. Durability of mitral valve repair in Barlow disease versus fibroelastic deficiency. J. Thorac. Cardiovasc. Surg. 2008, 135, 274-282. [CrossRef]

8. Suri, R.M.; Clavel, M.-A.; Schaff, H.V.; Michelena, H.I.; Huebner, M.; A Nishimura, R.; Enriquez-Sarano, M. Effect of Recurrent Mitral Regurgitation Following Degenerative Mitral Valve Repair. J. Am. Coll. Cardiol. 2016, 67, 488-498. [CrossRef]

9. Chan, V.; Ruel, M.; Hynes, M.; Chaudry, S.; Mesana, T.G. Impact of mitral annular calcification on early and late outcomes following mitral valve repair of myxomatous degeneration. Interact. Cardiovasc. Thorac. Surg. 2013, 17, 120-125. [CrossRef]

10. Pepi, M.; Tamborini, G.; Maltagliati, A.; Galli, C.A.; Sisillo, E.; Salvi, L.; Naliato, M.; Porqueddu, M.; Parolari, A.; Zanobini, M.; et al. Head-to-Head Comparison of Two- and Three-Dimensional Transthoracic and Transesophageal Echocardiography in the Localization of Mitral Valve Prolapse. J. Am. Coll. Cardiol. 2006, 48, 2524-2530. [CrossRef]

11. Salcedo, E.E.; Quaife, R.A.; Seres, T.; Carroll, J.D. A Framework for Systematic Characterization of the Mitral Valve by Real-Time Three-Dimensional Transesophageal Echocardiography. J. Am. Soc. Echocardiogr. 2009, 22, 1087-1099. [CrossRef]

12. Tamborini, G.; Muratori, M.; Maltagliati, A.; Galli, C.A.; Naliato, M.; Zanobini, M.; Alamanni, F.; Salvi, L.; Sisillo, E.; Fiorentini, C.; et al. Pre-operative transthoracic real-time three-dimensional echocardiography in patients undergoing mitral valve repair: Accuracy in cases with simple vs. complex prolapse lesions. Eur. J. Echocardiogr. 2010, 11, 778-785. [CrossRef]

13. Wei, J.; Hsiung, M.C.; Tsai, S.K.; Ou, C.-H.; Chang, C.-Y.; Chang, Y.C.; Lee, K.C.; Sue, S.-H.; Chou, Y.-P. The routine use of live three-dimensional transesophageal echocardiography in mitral valve surgery: Clinical experience. Eur. J. Echocardiogr. 2009, 11, 14-18. [CrossRef]

14. Chandra, S.; Salgo, I.S.; Sugeng, L.; Weinert, L.; Tsang, W.; Takeuchi, M.; Spencer, K.T.; O'Connor, A.; Cardinale, M.; Settlemier, S.; et al. Characterization of Degenerative Mitral Valve Disease Using Morphologic Analysis of Real-Time Three-Dimensional Echocardiographic Images. Circ. Cardiovasc. Imaging 2011, 4, 24-32. [CrossRef]

15. Zoghbi, W.A.; Adams, D.; Bonow, R.O.; Enriquez-Sarano, M.; Foster, E.; Grayburn, P.A.; Hahn, R.T.; Han, Y.; Hung, J.; Lang, R.M.; et al. Recommendations for Noninvasive Evaluation of Native Valvular Regurgitation. J. Am. Soc. Echocardiogr. 2017, 30, 303-371. [CrossRef]

16. Pepi, M.; Tamborini, G.; Galli, C.; Barbier, P.; Doria, E.; Berti, M.; Guazzi, M.; Fiorentini, C. A New Formula For Echo-Doppler Estimation of Right Ventricular Systolic Pressure. J. Am. Soc. Echocardiogr. 1994, 7, 20-26. [CrossRef] 
17. Carpentier, A. Cardiac valve surgery-The "French correction. " J. Thorac. Cardiovasc. Surg. 1983, 86, 323-337. [CrossRef]

18. Enriquez-Sarano, M.; Akins, C.W.; Vahanian, A. Mitral regurgitation. Lancet 2009, 373, 1382-1394. [CrossRef]

19. O'Gara, P.; Sugeng, L.; Lang, R.; Sarano, M.; Hung, J.; Raman, S.; Fischer, G.; Carabello, B.; Adams, D.; Vannan, M. The Role of Imaging in Chronic Degenerative Mitral Regurgitation. JACC Cardiovasc. Imaging 2008, 1, 221-237. [CrossRef]

20. Duran, C.M. Surgical techniques for the repair of anterior mitral leaflet prolapse. J. Card. Surg. 1999, 14, 471-481. [CrossRef]

21. Aubert, S.; Barreda, T.; Acar, C.; Leprince, P.; Bonnet, N.; Ecochard, R.; Pavie, A.; Gandjbakhch, I. Mitral valve repair for commissural prolapse: Surgical techniques and long term results. Eur. J. Cardio Thoracic Surg. 2005, 28, 443-447. [CrossRef]

22. Anyanwu, A.C.; Itagaki, S.; Chikwe, J.; El-Eshmawi, A.; Adams, D.H. A complexity scoring system for degenerative mitral valve repair. J. Thorac. Cardiovasc. Surg. 2016, 151, 1661-1670. [CrossRef]

23. Chikwe, J.; Adams, D.H.; Su, K.N.; Anyanwu, A.C.; Lin, H.-M.; Goldstone, A.B.; Lang, R.M.; Fischer, G.W. Can three-dimensional echocardiography accurately predict complexity of mitral valve repair? Eur. J. Cardio Thoracic Surg. 2012, 41, 518-524. [CrossRef]

24. Chang, B.-C.; Youn, Y.-N.; Ha, J.-W.; Lim, S.-H.; Hong, Y.-S.; Chung, N. Long-term clinical results of mitral valvuloplasty using flexible and rigid rings: A prospective and randomized study. J. Thorac. Cardiovasc. Surg. 2007, 133, 995-1003. [CrossRef]

25. Lancellotti, P.; Tribouilloy, C.; Hagendorff, A.; Popescu, B.A.; Edvardsen, T.; Pierard, L.A.; Badano, L.; Zamorano, J.L. Recommendations for the echocardiographic assessment of native valvular regurgitation: An executive summary from the European Association of Cardiovascular Imaging. Eur. Heart J. Cardiovasc. Imaging 2013, 14, 611-644. [CrossRef]

26. Fusini, L.; Ali, S.G.; Tamborini, G.; Muratori, M.; Gripari, P.; Maffessanti, F.; Celeste, F.; Guglielmo, M.; Cefalù, C.; Alamanni, F.; et al. Prevalence of Calcification of the Mitral Valve Annulus in Patients Undergoing Surgical Repair of Mitral Valve Prolapse. Am. J. Cardiol. 2014, 113, 1867-1873. [CrossRef]

27. Marsan, N.A.; Maffessanti, F.; Tamborini, G.; Gripari, P.; Caiani, E.G.; Fusini, L.; Muratori, M.; Zanobini, M.; Alamanni, F.; Pepi, M. Left atrial reverse remodeling and functional improvement after mitral valve repair in degenerative mitral regurgitation: A real-time 3-dimensional echocardiography study. Am. Heart J. 2011, 161, 314-321. [CrossRef]

28. Maffessanti, F.; Marsan, N.A.; Tamborini, G.; Sugeng, L.; Caiani, E.G.; Gripari, P.; Alamanni, F.; Jeevanandam, V.; Lang, R.M.; Pepi, M. Quantitative Analysis of Mitral Valve Apparatus in Mitral Valve Prolapse Before and After Annuloplasty: A Three-Dimensional Intraoperative Transesophageal Study. J. Am. Soc. Echocardiogr. 2011, 24, 405-413. [CrossRef]

29. Ashikhmina, E.A.; Schaff, H.V.; Suri, R.M.; Enriquez-Sarano, M.; Abel, M.D. Left ventricular remodeling early after correction of mitral regurgitation: Maintenance of stroke volume with decreased systolic indexes. J. Thorac. Cardiovasc. Surg. 2010, 140, 1300-1305. [CrossRef]

30. Suri, R.M.; Schaff, H.V.; A Dearani, J.; Sundt, T.M.; Daly, R.C.; Mullany, C.J.; Enriquez-Sarano, M.; Orszulak, T.A. Recovery of left ventricular function after surgical correction of mitral regurgitation caused by leaflet prolapse. J. Thorac. Cardiovasc. Surg. 2009, 137, 1071-1076. [CrossRef]

Publisher's Note: MDPI stays neutral with regard to jurisdictional claims in published maps and institutional affiliations.

(C) 2020 by the authors. Licensee MDPI, Basel, Switzerland. This article is an open access article distributed under the terms and conditions of the Creative Commons Attribution (CC BY) license (http://creativecommons.org/licenses/by/4.0/). 